Cite this: RSC Advances, 2013, 3, 3103

Received 31st October 2012, Accepted 20th December 2012

DOI: $10.1039 / \mathrm{c} 2 \mathrm{ra} 22715 \mathrm{k}$

www.rsc.org/advances

\section{Electronic substituent effects on hydrogen-bonding motifs modulate supramolecular polymerisation $\dagger$}

\begin{abstract}
Maria L. Pellizzaro, ${ }^{a}$ Julie Fisher ${ }^{a}$ and Andrew J. Wilson*ab
Hydrogen-bond assembled supramolecular polymers receive enormous interest as stimuli responsive materials that can be obtained using small easy to purify organic molecules. A key feature that determines materials properties in dilute solution is the strength of interaction between supramolecular synthons. In this work we illustrate that electronic substituents which are conjugated to the hydrogen-bonding motif can have subtle but significant effects on the degree of supramolecular polymerisation. Using ureidopyrimidines which contain electron donating phenolate and benzoate ester linkages in direct electronic communication with the self-complementary hydrogen-bonding motif, diffusion ordered spectroscopy (DOSY) demonstrates predictable differences in the extent of supramolecular polymerisation.
\end{abstract}

\section{Introduction}

Supramolecular polymers ${ }^{1,2}$ have received enormous interest as functional materials as a direct consequence of the emergent properties they elicit, notably stimuli responsive behaviour $^{1}$ and self-healing characteristics. ${ }^{3}$ Applications include scaffolds for biomedical purposes and conductive materials. ${ }^{2}$ A wide array of architectures have been assembled using the full gamut of non-covalent interactions; $;^{1,4}$ of these, hydrogen-bonding, ${ }^{5}$ owing to its tuneability and directionality has received considerable attention. A central concept in supramolecular polymer science is that the affinity between monomeric building blocks must be sufficiently high to confer materials properties in dilute solution, ${ }^{6,7}$ although lateral association also plays a defining role. ${ }^{8-10}$ Therefore, the design and synthesis of heterocyclic hydrogen-bonding motifs with well defined and high-affinity molecular recognition behaviour $^{11}$ plays a key role in defining the extent of supramolecular association and polymerisation.

Our group has previously reported on the design and synthesis of a series of hydrogen-bonding motifs capable of forming triply ${ }^{12-14}$ and quadruply ${ }^{15}$ hydrogen-bonded heterodimers that can be used to assemble supramolecular polyurethane elastomers. ${ }^{16}$ Using one of these heterodimers-the ureidoimidazole/amiodisocytosine $\mathbf{1 2}$ motif (Fig. 1) -we illustrated that dimerisation affinity could be tuned over nearly two orders of magnitude, simply by

${ }^{a}$ School of Chemistry, University of Leeds, Woodhouse Lane, Leeds, LS2 9JT, United Kingdom. E-mail: A.J.Wilson@leeds.ac.uk; Fax: +44 (0)113 3436565;

Tel: +44 (0)113 3431409

${ }^{b}$ Astbury Centre for Structural Molecular Biology, University of Leeds, Woodhouse

Lane, Leeds, LS2 9JT, United Kingdom

$\dagger$ Electronic supplementary information (ESI) available: NMR spectra. See DOI: $10.1039 / \mathrm{c} 2 \mathrm{ra} 22715 \mathrm{k}$ changing remote (but conjugated) electronic substituents. ${ }^{13}$ We were keen to extend this observation further and probe the extent to which supramolecular polymerisation is affected by substituent effects on the non-covalent interactions between supramolecular monomers. Herein we illustrate that supramolecular polymerisation is indeed effected in a subtle manner by proximal electronic substituents.

\section{Results and discussion}

\section{Design and synthesis}

To test our hypothesis that remote substituent control over hydrogen-bond mediated dimerisation translates into measurable differences in supramolecular polymerisation it was necessary to identify a suitable synthetic test system. We have previously reported that remote substituents can affect the

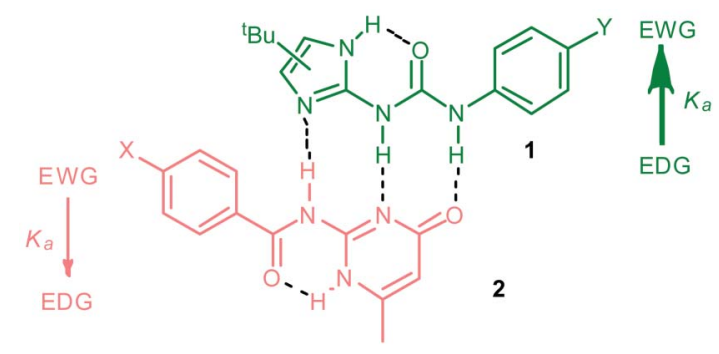

Fig. 1 Triply hydrogen-bonded heterodimer $\mathbf{1 \cdot 2}$ illustrating how substituent effects can modulate dimerisation affinity. The substituent has a major effect on the hydrogen-bonding ability of $\mathbf{1}$ with electron-withdrawing substituents leading to greater $\mathbf{H}$-bond acidity of the anilide whereas in $\mathbf{2}$ only minor effects are observed because the carbonyl group insulates against the effect of the substituent. 


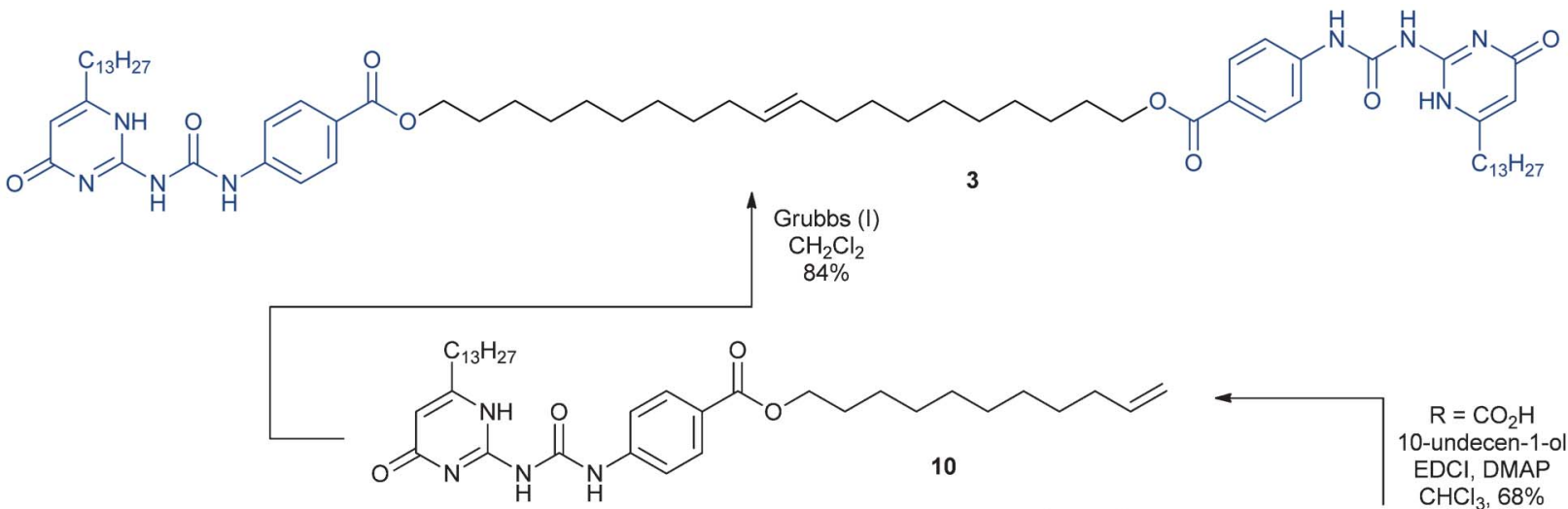

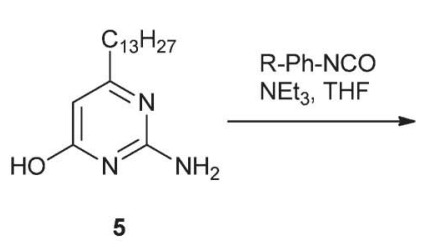
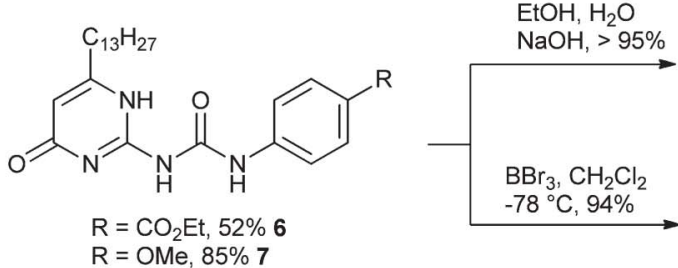<smiles>[R]OC(=O)OCc1cc(=O)nc(NC(=O)Nc2ccc([R])cc2)[nH]1</smiles>
$\mathrm{R}=\mathrm{OMe}, 85 \% 7$

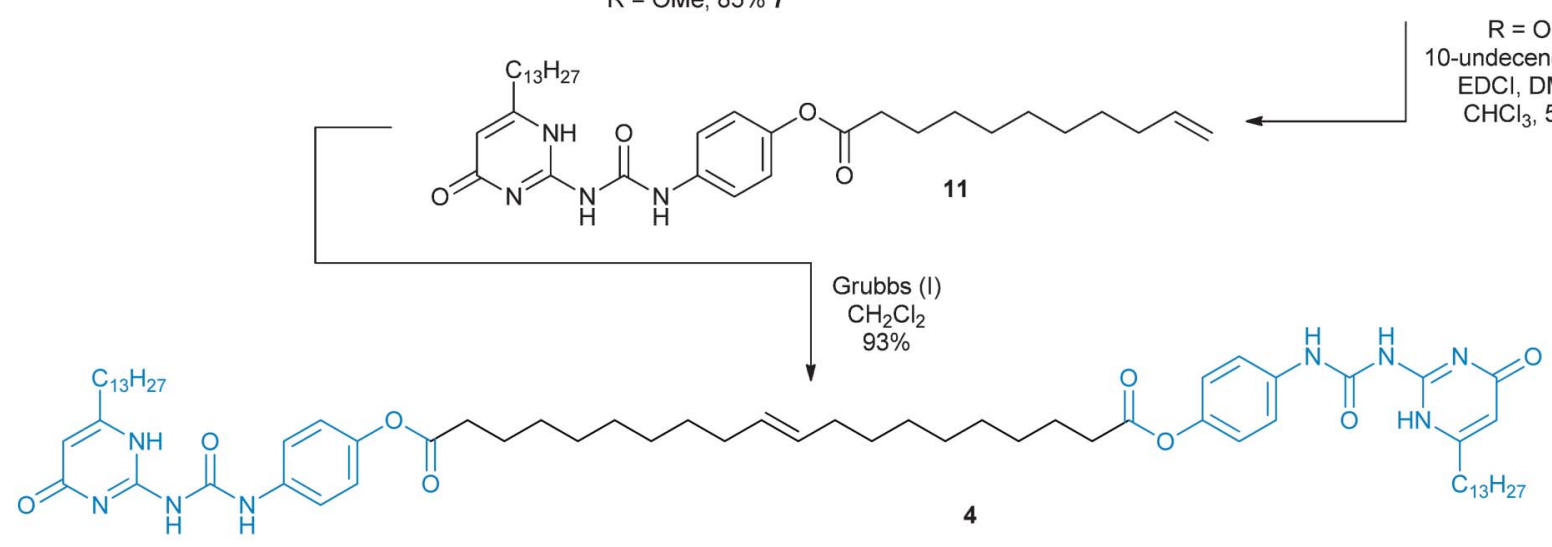

Scheme 1 Synthesis of ditopic UPy bases supramolecular monomers $\mathbf{3}$ and $\mathbf{4}$.

binding affinity of triply hydrogen bonded systems. ${ }^{13}$ However, we chose not to use the triple hydrogen bond dimer in this study because it was considered (a) too complex a system for the purpose of this investigation in that it would be difficult to ascribe any changes in supramolecular polymerisation to a change in the recognition properties of either component of the heterodimer and (b) too low affinity a system to get significant polymerisation in dilute solutions. This challenge was compounded further by the fact that different substituents could potentially exert other effects on the supramolecular polymerisation of a ditopic monomer. Thus a simpler ditopic building block capable of homodimerisation was desired: the ditopic ureidopyrimidines (UPys) 3 and $\mathbf{4}$ presented themselves as suitable building blocks. UPys 3 and $\mathbf{4}$ have the advantage of both being esters hence minimising any differences in supramolecular polymerisation arising as a consequence of interactions made by the remote substituent group, however they should experience different effects on hydrogen-bonding propensity. In 3 , the ester group is linked to the UPy motif via the electron withdrawing carboxy functional group and in $\mathbf{4}$ through the electron donating oxygen group. Intermediate acid $\mathbf{8}$ and phenol $\mathbf{9}$ were synthesised following known standard methods based on literature procedures as illustrated in Scheme 1. We attempted to link these intermediates by ester formation with long chain diols and diacids respectively, however these reactions failed to yield isolable target material. We thus sought a different strategy whereby ester formation was performed with a long chain acid or alcohol possessing an alkene to yield a metathesis substrate. Upon reaction with Grubbs' first generation catalyst, the desired targets $\mathbf{3}$ and $\mathbf{4}$ were isolated as a mixture of $E / Z$ isomers $(1: 1)$.

\section{Supramolecular polymerisation}

The ${ }^{1} \mathrm{H}$ NMR spectra of both 3 and $\mathbf{4}$ exhibit the characteristic low field resonances associated with hydrogen-bonded NH's in UPy derivatives. ${ }^{17}$ Notably, as the concentration was decreased we observed that the ${ }^{1} \mathrm{H}$ NMR peaks sharpened for both compounds (see ESI $\dagger$ ), indicative of smaller assemblies being present and hence depolymerisation, as should be observed for reversibly assembled polymers. To characterise the molecular size of the supramolecular polymers in dilute 
Table 1 Diffusion coefficient $(D)$ and degree of polymerisation $(D P)$ for $\mathbf{3}$ and $\mathbf{4}$

\begin{tabular}{|c|c|c|c|c|}
\hline Concentration (mM) & $D\left(\times 10^{-10} \mathrm{~m}^{2} \mathrm{~s}^{-1}\right)$ & $D P$ & $D\left(10^{-10} \mathrm{~m}^{2} \mathrm{~s}^{-1}\right)$ & $D P$ \\
\hline 30 & $2.315 \pm 0.005$ & $16.58 \pm 0.48$ & $2.089 \pm 0.010$ & $12.57 \pm 0.29$ \\
\hline 10 & $5.817 \pm 0.007$ & $1.05 \pm 0.03$ & $5.040 \pm 0.025$ & $0.90 \pm 0.02$ \\
\hline 1 & $5.903 \pm 0.070$ & 1.00 & $4.858 \pm 0.060$ & 1.00 \\
\hline
\end{tabular}

solution we identified DOSY as an ideal technique to monitor aggregate size. DOSY can be used to measure the size of the assemblies that are present in solution, and has been used to study supramolecular polymerisation previously. ${ }^{18-20}$ Smaller assemblies exhibit larger diffusion coefficients $(D)$ consistent with more rapid tumbling in solution. The diffusion coefficient was therefore measured for both UPy $\mathbf{3}$ and $\mathbf{4}$ at different concentrations (Table 1).

As might be expected upon increasing the concentration, the diffusion coefficient decreases consistent with an increase in molecular size. Because $D$ was very similar for 10 and $1 \mathrm{mM}$ in both polymers we reasoned that this was the smallest assembly that could be formed in solution; probably representing a single molecule. On this basis, the degree of polymerisation $(D P)$ could be calculated (Table 1); firstly the molecular weights $(M W)$ of the assemblies at each concentration were calculated (eqn (1)) where $D_{[\text {low }]}$ was the $D$ for $1 \mathrm{mM}$ solutions and $M W_{[\text {low] }}$ was assumed to be the monomer. The $D P$ was then calculated using eqn (2).

$$
\begin{gathered}
\frac{D_{[\mathrm{LOW}]}}{D_{[\mathrm{HIGH}]}}=\frac{\sqrt[3]{M W_{\mathrm{LOW}}}}{\sqrt[3]{M W_{\mathrm{HIGH}}}} \\
D P=\frac{M W_{\mathrm{HIGH}}}{M W_{\mathrm{LOW}}}
\end{gathered}
$$

A plot of $D P$ against concentration for both polymers $\mathbf{3}$ and $\mathbf{4}$ (Fig. 2) reveals two features (a) that supramolecular polymerisation proceeds at lower concentrations for the UPy with the electron withdrawing group (i.e. 3) and (b) that the size of the

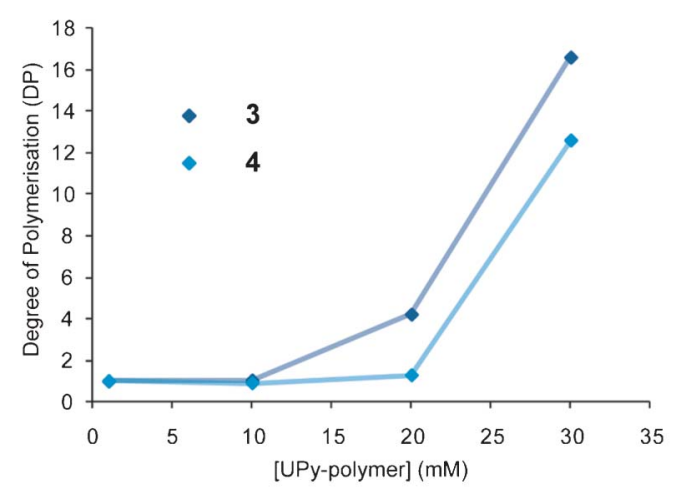

Fig. 2 Graph showing the correlation between the concentration and DP for both $\mathbf{3}$ (dark blue) and $\mathbf{4}$ (light blue). supramolecular polymer formed by UPy 3 is larger than that formed by UPy 4 . This is consistent with a higher dimerisation affinity that would be predicted on the basis of substituent effects - the carbonyl group in $\mathbf{3}$ is electron withdrawing and should enhance the acidity of the anilide proton whereas the phenol ether group in $\mathbf{4}$ is electron donating and should decrease the acidity of the anilide proton.

\section{Conclusions}

In conclusion, we have described the design and synthesis of two structurally similar UPy derivatives $\mathbf{3}$ and $\mathbf{4}$ that allowed us to probe proximal substituent effects on dimerisation affinity in the context of their impact on supramolecular polymerisation. Our results illustrate that the degree of polymerisation can be affected in a predictable manner; electron withdrawing substituents enhance polymerisation and electron-donating substituents diminish polymerisation. The effect is small but significant enough to warrant careful consideration of the linking group chemistry that is used to conjugate supramolecular synthons to macromolecular building blocks. The effect could also be used to exert fine control over materials properties.

\section{Experimental section}

\section{General points}

All reagents were purchased from Aldrich or Alfa-Aesar and used without further purification unless otherwise stated. Where anhydrous solvents were required, tetrahydrofuran was freshly distilled from sodium benzophenone ketyl radical and dichloromethane was freshly distilled from calcium hydride, or they were obtained using a solvent purification system from Innovative Technology Inc. PureSolv. Chloroform was freshly distilled from calcium chloride under a nitrogen atmosphere. Anhydrous DMF was obtained "sure-sealed" from SigmaAldrich. Triethylamine was distilled from calcium hydride and stored, under nitrogen, over potassium hydroxide pellets. All non-aqueous reactions were carried out under a nitrogen atmosphere. Analytical thin layer chromatography (TLC) was conducted using Merck Kieslegel $0.25 \mathrm{~mm}$ silica gel pre-coated aluminium plates with fluorescent indicator active at $\mathrm{UV}_{245}$. Purification by column chromatography was carried out using Merck Kieselgel 60 silica gel. NMR spectra were obtained using. Bruker DMX500 or Bruker AMD300 spectrometers operating at 
$500 \mathrm{MHz}$ or $300 \mathrm{MHz}$ for ${ }^{1} \mathrm{H}$ spectra and $100 \mathrm{MHz}$ or $75 \mathrm{MHz}$ for ${ }^{13} \mathrm{C}$ spectra as stated. Proton spectra are referenced to TMS at $0.00 \mathrm{ppm}$, and carbon spectra to $\mathrm{CDCl}_{3}$ at $77.4 \mathrm{ppm}$, unless otherwise stated. Melting points were determined using a Griffin D5 variable temperature apparatus and are uncorrected. IR spectra were obtained using Perkin-Elmer FTIR spectrometer. Microanalysis was carried out on a Carlo Erba Elemental Analyser MOD 1106 instrument. High Resolution Mass Spectra (HRMS) were recorded on a Micromass GCT Premier using electron impact ionisation (EI) or a Bruker Daltonics microTOF using electrospray ionisation (ESI).

\section{2-Amino-6-tridecylpyrimidin-4-ol 5}

Was synthesised following minor modifications to a literature procedures. $^{21}$ Triethylamine $(50.0 \mathrm{~mL}, 360 \mathrm{mmol})$ was added to a suspension of potassium ethyl malonate (40.8 g, 240 $\mathrm{mmol})$ in acetonitrile $(250 \mathrm{~mL})$ stirred at $0{ }^{\circ} \mathrm{C}$. The reaction mixture was stirred for $15 \mathrm{~min}$ before magnesium chloride $(28.5 \mathrm{~g}, 300 \mathrm{mmol})$ in acetonitrile $(80 \mathrm{~mL})$ was added and allowed to warm to $10{ }^{\circ} \mathrm{C}$. After stirring for $2 \mathrm{~h}$ the reaction mixture was cooled to $0{ }^{\circ} \mathrm{C}$ before myristoyl chloride $(32.6 \mathrm{~mL}$, $120 \mathrm{mmol}$ ) was added dropwise. The reaction mixture was warmed to room temperature and stirred for $16 \mathrm{~h}$ before the solvents were evaporated in vacuo. The resultant solid was dissolved in ether $(350 \mathrm{~mL})$ and washed with $30 \%$ aqueous hydrochloric acid $(250 \mathrm{~mL})$ and saturated aqueous sodium bicarbonate $(100 \mathrm{~mL})$ before the organics were dried over magnesium sulphate, filtered and evaporated in vacuo. The resultant solid was purified by column chromatography (chloroform) to give ethyl 3-oxohexadecanoate (26.9 g, 75\%) as a colourless powder, which was used in the next step without further purification. Guanidinium carbonate $(12.8 \mathrm{~g}$, $142.6 \mathrm{mmol}$ ) was added to a solution of 3-oxohexadecanoate $(25.0 \mathrm{~g}, 83.9 \mathrm{mmol})$ and potassium tert-butoxide (9.4 g, 83.9 $\mathrm{mmol})$ in $\mathrm{EtOH}(300 \mathrm{~mL})$ and the reaction mixture was heated to reflux for 3 days. After cooling the reaction mixture was filtered and the filtrate was evaporated in vacuo. The resultant solid was dissolved in water $(500 \mathrm{~mL})$ and the solution was acidified to $\mathrm{pH} 6$ (acetic acid). The resultant suspension was filtered and the solid washed with acetone and ether before being crystallised (propan-2-ol) to give the 2-amino-6-tridecylpyrimidin-4-ol as a cream coloured powder; m.p. 162-165 C; $R_{\mathrm{f}}$ 0.19 (1 : 9 methanol : dichloromethane); $\delta_{\mathrm{H}}(300 \mathrm{MHz}$, DMSO$\left.\mathrm{d}_{6}\right) ; 6.58\left(2 \mathrm{H}, \mathrm{s}, \mathrm{NH}_{2}\right), 5.33(1 \mathrm{H}, \mathrm{s}, \mathrm{ArCH}), 2.20(2 \mathrm{H}, \mathrm{t}, J=6.0 \mathrm{~Hz}$, $\left.\mathrm{CH}_{2}\right), 1.51\left(2 \mathrm{H}, \mathrm{m}, \mathrm{CH}_{2}\right), 1.23\left(20 \mathrm{H}, \mathrm{m}, 10 \times \mathrm{CH}_{2}\right), 0.85(3 \mathrm{H}, \mathrm{t}, J$ $\left.=6.0 \mathrm{~Hz}, \mathrm{CH}_{3}\right)$; the molecule was insufficiently soluble to obtain a meaningful ${ }^{13} \mathrm{C}$ spectrum; $v_{\max } / \mathrm{cm}^{-1}$ (neat); 3360, 3144, 2919, 2850, 2679 (br), 1637, 1468, 1401; ESI-HRMS found $m / z 294.2529[\mathrm{M}+\mathrm{H}]^{+}, \mathrm{C}_{17} \mathrm{H}_{32} \mathrm{~N}_{3} \mathrm{O}$ requires 294.2540.

\section{Ethyl 4-(3-(4-oxo-6-tridecyl-1,4-dihydropyrimidin-2- yl)ureido)benzoate 6}

Ethyl-4-isocyanatobenzoate $(0.71 \mathrm{~g}, 3.75 \mathrm{mmol})$ was added to a refluxing solution of 2-amino-6-tridecylpyrimidin-4-ol (1.00 g, $3.41 \mathrm{mmol})$ and triethylamine $(0.48 \mathrm{~mL}, 3.75 \mathrm{mmol})$ in tetrahydrofuran $(50 \mathrm{~mL})$. The reaction mixture was then stirred at reflux for $18 \mathrm{~h}$ before being allowed to cool and the volatiles evaporated in vacuo. The resultant solid was suspended in ethyl acetate $(50 \mathrm{~mL})$ and water $(50 \mathrm{~mL})$ was added. The suspension was filtered and sonicated in ethylacetate $(50 \mathrm{~mL})$ before being filtered and washed (diethyl ether) to give ethyl 4-(3-(4-oxo-6-tridecyl-1,4-dihydropyrimidin-2-yl)ureido)benzoate $(1.22 \mathrm{~g}, 74 \%)$ as a colourless powder; m.p. 218$220{ }^{\circ} \mathrm{C} ; R_{\mathrm{f}} 0.38$ (1:99 methanol : dichloromethane); $\delta_{\mathrm{H}}(300$ $\left.\mathrm{MHz}_{\mathrm{CDCl}}\right)$; $12.95(1 \mathrm{H}, \mathrm{s}, \mathrm{NH}), 12.52(1 \mathrm{H}, \mathrm{s}, \mathrm{NH}), 12.32(1 \mathrm{H}, \mathrm{s}$, $\mathrm{NH}), 8.07(2 \mathrm{H}, \mathrm{d}, J=8.7 \mathrm{~Hz}, \operatorname{ArCH}), 7.86(2 \mathrm{H}, \mathrm{d}, J=8.7 \mathrm{~Hz}$, $\operatorname{ArCH}), 5.94$ (1H, s, ArCH), $4.41\left(2 \mathrm{H}, \mathrm{q}, J=7.2 \mathrm{~Hz}, \mathrm{CH}_{2}\right), 2.47$ $\left(2 \mathrm{H}, \mathrm{t}, J=7.7 \mathrm{~Hz}, \mathrm{CH}_{2}\right), 1.65\left(4 \mathrm{H}, \mathrm{m}, 2 \times \mathrm{CH}_{2}\right), 1.44(3 \mathrm{H}, \mathrm{t}, J=$ $\left.7.2 \mathrm{~Hz}, \mathrm{CH}_{3}\right), 1.32\left(18 \mathrm{H}, \mathrm{m}, 9 \times \mathrm{CH}_{2}\right), 0.92(3 \mathrm{H}, \mathrm{t}, J=6.6 \mathrm{~Hz}$, $\mathrm{CH} 3) ; \delta_{\mathrm{C}}\left(75 \mathrm{MHz}, \mathrm{CDCl}_{3}\right) ; 172.8,166.2,154.4,154.3,152.9$, $142.8,130.5,125.3,119.3,105.9,60.8,32.4,31.9,29.6-29.2(\times$ $7), 28.9,26.3,22.7,14.4,14.1 ; v_{\max } / \mathrm{cm}^{-1}$ (neat); 3466-2850, 1698, 1650; ESI-HRMS found $m / z \quad 485.3139 \quad[\mathrm{M}+\mathrm{H}]^{+}$, $\mathrm{C}_{27} \mathrm{H}_{41} \mathrm{~N}_{4} \mathrm{O}_{4}$ requires 485.3122 .

\section{1-(4-Methoxyphenyl)-3-(4-oxo-6-tridecyl-1,4-dihydropyrimidin- 2-yl)urea 7}

4-Methoxyphenylisocyanate $(0.24 \mathrm{~mL}, 1.90 \mathrm{mmol})$ was added to a refluxing mixture of the 2-amino-6-tridecylpyrimidin-4-ol $(0.50 \mathrm{~g}, 1.71 \mathrm{mmol})$ and triethylamine $(0.24 \mathrm{~mL}, 1.71 \mathrm{mmol})$ in tetrahydrofuran $(20 \mathrm{~mL})$. The reaction mixture was then stirred at reflux for $18 \mathrm{~h}$ before being allowed to cool and the volatiles evaporated in vacuo. The resultant solid was triturated in hot chloroform $(50 \mathrm{~mL})$, filtered and the filtrate evaporated to give the crude product which was crystallised (chloroform/methanol) to give 1-(4-methoxyphenyl)-3-(4-oxo-6-tridecyl-1,4-dihydropyrimidin-2-yl)urea (0.55 g, 73\%) as colourless needles; m.p. $121-123{ }^{\circ} \mathrm{C}$ (Found: C, 67.7; H, 8.65; N, 12.7; $\mathrm{C}_{25} \mathrm{H}_{38} \mathrm{~N}_{4} \mathrm{O}_{3}$ requires $\mathrm{C}, 67.8 ; \mathrm{H}, 8.65 ; \mathrm{N}, 12.7 \%) ; R_{\mathrm{f}} 0.57$ (1:1 ethyl acetate : hexane); $\delta_{\mathrm{H}}\left(300 \mathrm{MHz}, \mathrm{CDCl}_{3}\right) ; 13.12(1 \mathrm{H}, \mathrm{s}, \mathrm{NH})$, $12.27(1 \mathrm{H}, \mathrm{s}, \mathrm{NH}), 12.10(1 \mathrm{H}, \mathrm{s}, \mathrm{NH}), 7.61(2 \mathrm{H}, \mathrm{d}, J=9.1 \mathrm{~Hz}$, $\mathrm{ArCH}), 6.93(2 \mathrm{H}, \mathrm{d}, J=9.1 \mathrm{~Hz}, \mathrm{ArCH}), 5.94(1 \mathrm{H}, \mathrm{s}, \mathrm{ArCH}), 3.84$ $\left(3 \mathrm{H}, \mathrm{s}, \mathrm{OCH}_{3}\right), 2.50\left(2 \mathrm{H}, \mathrm{t}, J=7.5 \mathrm{~Hz}, \mathrm{CH}_{2}\right), 1.68\left(2 \mathrm{H}, \mathrm{m}, \mathrm{CH}_{2}\right)$, $1.60\left(4 \mathrm{H}, \mathrm{m}, 2 \times \mathrm{CH}_{2}\right), 1.32\left(16 \mathrm{H}, \mathrm{m}, 8 \times \mathrm{CH}_{2}\right), 0.92(3 \mathrm{H}, \mathrm{t}, J=$ $\left.6.8 \mathrm{~Hz}, \mathrm{CH}_{3}\right) ; \delta_{\mathrm{C}}\left(75 \mathrm{MHz}, \mathrm{CDCl}_{3}\right) ; 173.1,156.2,154.7,154.6$, $152.7,131.2,122.4,114.1,105.9,55.5,32.6,31.9,29.7-29.2(\times$ 7), 28.9, 26.7, 22.7, 14.2; $v_{\max } / \mathrm{cm}^{-1}$ (neat); 2916 (br), 1707, 1651, 1574, 1509; ESI-HRMS found $m / z$ 443.3017 $[\mathrm{M}+\mathrm{H}]^{+}$, $\mathrm{C}_{25} \mathrm{H}_{39} \mathrm{~N}_{4} \mathrm{O}_{3}$ requires 443.3017 .

\section{4-(3-(4-Oxo-6-tridecyl-1,4-dihydropyrimidin-2- yl)ureido)benzoic acid 8}

Synthesised following a literature procedure. ${ }^{22} 1 \mathrm{M}$ Aqueous sodium hydroxide $(4.12 \mathrm{~mL}, 4.12 \mathrm{mmol})$ was added to a suspension of ethyl 4-(3-(4-oxo-6-tridecyl-1,4-dihydropyrimidin-2-yl)ureido)benzoate (500 $\mathrm{mg}, 1.03 \mathrm{mmol})$ in ethanol (50 $\mathrm{mL}$ ) and the reaction mixture was heated to $70{ }^{\circ} \mathrm{C}$ for $18 \mathrm{~h}$. The solvent was then evaporated in vacuo and the resultant solid was dissolved in water $(25 \mathrm{~mL})$ and acidified with $10 \%$ aqueous hydrochloric acid. The reaction mixture was then filtered to give 4-(3-(4-oxo-6-tridecyl-1,4-dihydropyrimidin-2yl)ureido)benzoic acid (457 $\mathrm{mg}, 97 \%$ ) as a colourless solid; m.p. $256-257{ }^{\circ} \mathrm{C} ; R_{\mathrm{f}} 0.39$ (1: 9 methanol : dichloromethane); $\delta_{\mathrm{H}}\left(300 \mathrm{MHz}, \mathrm{DMSO}_{6}\right) ; 7.91(2 \mathrm{H}, \mathrm{d}, J=9.0 \mathrm{~Hz}, 2 \times \mathrm{ArCH})$, $7.64(2 \mathrm{H}, \mathrm{d}, J=9.0 \mathrm{~Hz}, 2 \times \mathrm{ArCH}), 5.84(1 \mathrm{H}, \mathrm{s}, \mathrm{ArCH}), 2.44(2 \mathrm{H}$, $\left.\mathrm{t}, J=7.5 \mathrm{~Hz}, \mathrm{CH}_{2}\right), 1.59\left(2 \mathrm{H}, \mathrm{m}, \mathrm{CH}_{2}\right), 1.21\left(20 \mathrm{H}, \mathrm{m}, 10 \times \mathrm{CH}_{2}\right)$, $0.83\left(3 \mathrm{H}, \mathrm{t}, J=6.0 \mathrm{~Hz}, \mathrm{CH}_{3}\right)$; the molecule was insufficiently soluble to obtain a meaningful ${ }^{13} \mathrm{C}$ spectrum; $v_{\max } / \mathrm{cm}^{-1}$ 
(neat); 3200-2343, 1689, 1656; ESI-HRMS found $\mathrm{m} / \mathrm{z} 438.2747$ $\left[M-\mathrm{H}_{2} \mathrm{O}\right]^{-}, \mathrm{C}_{25} \mathrm{H}_{34} \mathrm{~N}_{4} \mathrm{O}_{3}$ requires 438.2631.

\section{1-(4-Hydroxyphenyl)-3-(4-oxo-6-tridecyl-1,4-dihydropyrimidin- 2-yl)urea 9}

Synthesised following literature procedures. ${ }^{23}$ Boron tribromide ( $3.4 \mathrm{~mL}, 1 \mathrm{M}$ in dichloromethane, $3.39 \mathrm{mmol}$ ) was added dropwise to a suspension of 1-(4-methoxyphenyl)-3-(4-oxo-6tridecyl-1,4-dihydropyrimidin-2-yl)urea (500 mg, $1.13 \mathrm{mmol}$ ) in dichloromethane $(10 \mathrm{~mL})$ cooled to $-78{ }^{\circ} \mathrm{C}$. The reaction mixture was then allowed to warm to room temperature and was stirred for $20 \mathrm{~h}$. Water $(10 \mathrm{~mL})$ was then added dropwise before the reaction mixture was filtered and the resultant solid was triturated with chloroform to give 1-(4-hydroxyphenyl)-3(4-oxo-6-tridecyl-1,4-dihydropyrimidin-2-yl)urea (448 mg, 93\%) as a colourless solid; m.p. $175-176{ }^{\circ} \mathrm{C} ; R_{\mathrm{f}} 0.39$ methanol : dichloromethane); $\delta_{\mathrm{H}}\left(300 \mathrm{MHz}, \mathrm{DMSO}-\mathrm{d}_{6}\right) ; 9.80(1 \mathrm{H}, \mathrm{s}, \mathrm{OH})$, $7.25(2 \mathrm{H}, \mathrm{d}, J=8.7 \mathrm{~Hz}, 2 \times \mathrm{ArCH}), 6.73(2 \mathrm{H}, \mathrm{d}, J=8.7 \mathrm{~Hz}, 2 \times$ $\operatorname{ArCH}), 5.84$ (1H, s, ArCH), $2.43\left(2 \mathrm{H}, \mathrm{t}, J=7.4 \mathrm{~Hz}, \mathrm{CH}_{2}\right), 1.59$ $\left(2 \mathrm{H}, \mathrm{m}, \mathrm{CH}_{2}\right), 1.22\left(20 \mathrm{H}, \mathrm{m}, 10 \times \mathrm{CH}_{2}\right), 0.85(3 \mathrm{H}, \mathrm{t}, J=6.6 \mathrm{~Hz}$, $\left.\mathrm{CH}_{3}\right) ; \delta_{\mathrm{C}}\left(75 \mathrm{MHz}, \mathrm{DMSO}-\mathrm{d}_{6}\right)$; 163.6, 163.4, 154.1, 153.5, 152.1, 129.5, 121.7, 115.7, 104.2, 36.1, 31.6, 29.4-29.1 (× 7), 28.7, 27.6, 22.4, 14.3; $v_{\max } / \mathrm{cm}^{-1}$ (neat); 3234-2853 (br), 1695, 1646, $1627,1562,1505,1447,1222,834$; ESI-HRMS found $\mathrm{m} / \mathrm{z}$ $429.2870[\mathrm{M}+\mathrm{H}]^{+}, \mathrm{C}_{24} \mathrm{H}_{37} \mathrm{~N}_{4} \mathrm{O}_{3}$ requires 429.2860.

\section{Undec-10-enyl 4-(3-(4-oxo-6-tridecyl-1,4-dihydropyrimidin-2- yl)ureido) benzoate 10}

10-Undecen-1-ol (358_L, $1.79 \mathrm{mmol})$ was added to a solution of 4-(3-(4-oxo-6-tridecyl-1,4-dihydropyrimidin-2-yl)ureido)benzoic acid (900 mg, $1.97 \mathrm{mmol})$, dimethylaminopyridine (328 $\mathrm{mg}, 2.69 \mathrm{mmol}$ ) and EDCI (412 $\mathrm{mg}, 2.15 \mathrm{mmol}$ ) in chloroform $(50 \mathrm{~mL})$ and the reaction mixture was heated to reflux for 3 day. It was then allowed to cool to room temperature before the solvent was evaporated in vacuo and the resultant solid was purified by column chromatography (gradient elution: $0: 1-$ 1: 19 methanol : dichloromethane) to give undec-10-enyl 4-(3(4-oxo-6-tridecyl-1,4-dihydropyrimidin-2-yl)ureido) benzoate (740 mg, 68\%) as a colourless powder; m.p. $122-125{ }^{\circ} \mathrm{C} ; R_{\mathrm{f}}$ 0.51 (1 : 19 ether : chloroform); $\delta_{\mathrm{H}}\left(500 \mathrm{MHz}, \mathrm{CDCl}_{3}\right) ; 12.96$ (1H, s, NH), 12.48 (1H, s, NH), $12.33(1 \mathrm{H}, \mathrm{s}, \mathrm{NH}), 8.03(2 \mathrm{H}, \mathrm{d}, J$ $=8.3 \mathrm{~Hz}, \mathrm{ArCH}), 7.82(2 \mathrm{H}, \mathrm{d}, J=8.3 \mathrm{~Hz}, \mathrm{ArCH}), 5.96(1 \mathrm{H}, \mathrm{s}$, $\operatorname{ArCH}), 5.82(1 \mathrm{H}, \mathrm{ddt}, J=11.0,17.0,6.6 \mathrm{~Hz}, \mathrm{CH}), 4.97$ (2H, ddd, $\left.J=11.0,17.0,32.3 \mathrm{~Hz}, \mathrm{CH}_{2}\right), 4.30\left(2 \mathrm{H}, \mathrm{t}, J=6.6 \mathrm{~Hz}, \mathrm{CH}_{2}\right), 2.52$ $\left(2 \mathrm{H}, \mathrm{t}, J=7.2 \mathrm{~Hz}, \mathrm{CH}_{2}\right), 2.05\left(2 \mathrm{H}, \mathrm{q}, J=7.2 \mathrm{~Hz}, \mathrm{CH}_{2}\right), 1.79-1.26$ $\left(36 \mathrm{H}, \mathrm{m}\right.$, alkyl), $0.87\left(3 \mathrm{H}, \mathrm{t}, J=6.9 \mathrm{~Hz}, \mathrm{CH}_{3}\right) ; \delta_{\mathrm{C}}(75 \mathrm{MHz}$, $\left.\mathrm{CDCl}_{3}\right)$; 172.9, 166.3, 154.4, 154.3, 153.0, 142.8, 139.2, 130.6, $125.4,119.4,114.2,106.0,65.0,33.9,32.5,32.0,29.7-28.8$ ( $\times$ 14), 26.4, 26.1, 22.7, 14.2; $v_{\max } / \mathrm{cm}^{-1}$ (neat); 3454, 2922, 2850, 1714, 1696, 1660; ESI-MS found $m / z 609.4[\mathrm{M}+\mathrm{H}]^{+}, \mathrm{C}_{36} \mathrm{H}_{56} \mathrm{H}_{4} \mathrm{O}_{4}$ requires 609.4 .

\section{4-(3-(4-Oxo-6-tridecyl-1,4-dihydropyrimidin-2-yl)ureido)phenyl undec-10-enoate 11}

10-Undecenoic acid (473 $\mathrm{mg}, 2.57 \mathrm{mmol})$ was added to a solution of 1-(4-hydroxyphenyl)-3-(4-oxo-6-tridecyl-1,4-dihydropyramidn-2-yl)urea (1.00 g, $2.34 \mathrm{mmol}$ ), DMAP (428 mg, 3.50 $\mathrm{mmol})$ and EDCI $(538 \mathrm{mg}, 2.80 \mathrm{mmol})$ in $\mathrm{CHCl}_{3}(50 \mathrm{~mL})$ and the reaction mixture was heated to reflux for $15 \mathrm{~h}$ before being allowed to cool to room temperature. The volatiles were then removed in vacuo and the resultant solid was purified by column chromatography (gradient elution: 0 : 1-1: 9 methanol : dichloromethane) and crystallisation (chloroform : methanol) to give the 4-(3-(4-oxo-6-tridecyl-1,4-dihydropyrimidin-2-yl)ureido)phenyl undec-10-enoate (758 $\mathrm{mg}, 54 \%)$ as a colourless powder; m.p. $128-130{ }^{\circ} \mathrm{C}$ (Found: C, 70.5; H, 9.15; $\mathrm{N}, 9.5 ; \mathrm{C}_{35} \mathrm{H}_{54} \mathrm{~N}_{4} \mathrm{O}_{4}$ requires C, 70.7; $\left.\mathrm{H}, 9.15 ; \mathrm{N}, 9.4 \%\right) ; R_{\mathrm{f}} 0.28$ (1 : 4 ethyl acetate : hexane); $\delta_{\mathrm{H}}\left(300 \mathrm{MHz}, \mathrm{CDCl}_{3}\right) ; 12.87(1 \mathrm{H}$, s, NH), $12.22(1 \mathrm{H}, \mathrm{s}, \mathrm{NH}), 12.11(1 \mathrm{H}, \mathrm{s}, \mathrm{NH}), 7.66(2 \mathrm{H}, \mathrm{d}, J=9.0$ $\mathrm{Hz}, 2 \times \mathrm{ArCH}), 6.97(2 \mathrm{H}, \mathrm{d}, J=9.0 \mathrm{~Hz}, 2 \times \mathrm{ArCH}), 5.75(1 \mathrm{H}, \mathrm{m}$, $\mathrm{CH}), 5.73(1 \mathrm{H}, \mathrm{s}, \mathrm{ArCH}), 4.91\left(2 \mathrm{H}, \mathrm{dd}, J=15.3,22.2 \mathrm{~Hz}, \mathrm{CH}_{2}\right)$, $2.47\left(2 \mathrm{H}, \mathrm{t}, J=7.4 \mathrm{~Hz}, \mathrm{CH}_{2}\right), 2.24\left(2 \mathrm{H}, \mathrm{t}, J=7.5 \mathrm{~Hz}, \mathrm{CH}_{2}\right), 1.98$ $\left(2 \mathrm{H}, \mathrm{q}, J=6.9 \mathrm{~Hz}, \mathrm{CH}_{2}\right), 1.68\left(2 \mathrm{H}, \mathrm{m}, \mathrm{CH}_{2}\right), 1.48\left(2 \mathrm{H}, \mathrm{m}, \mathrm{CH}_{2}\right)$, 1.32-1.19 (30H, m, $\left.15 \times \mathrm{CH}_{2}\right), 0.81\left(3 \mathrm{H}, \mathrm{t}, J=6.6 \mathrm{~Hz}, \mathrm{CH}_{3}\right) ; \delta_{\mathrm{C}}$ (75 MHz, $\left.\mathrm{CDCl}_{3}\right)$; 173.0, 172.2, 154.5 (× 2), 152.9, 146.7, 139.2, $135.9,121.8,121.2,114.2,106.0,34.4,33.8,32.5$, 31.9, 29.728.8 ( $\times 13$ ), 26.7, 24.9, 22.7, 14.1; $\delta_{\max } / \mathrm{cm}^{-1}$ (neat); 3143, 2924, 281, 1749, 1697, 1580, 1505, 1201; ESI-HRMS found $\mathrm{m} / \mathrm{z}$ $617.4018[\mathrm{M}+\mathrm{Na}]^{+}, \mathrm{C}_{35} \mathrm{H}_{54} \mathrm{~N}_{4} \mathrm{NaO}_{4}$ requires 617.4037 .

\section{(E,Z)-Icos-10-ene-1,20-diyl-bis(4-(3-4-oxo-6-tridecyl-1,4- dihydropyrimidin-2-yl)ureido)benzoate) 3}

Grubbs' (I) catalyst (10 mg, $0.01 \mathrm{mmol})$ in degassed dichloromethane $(2 \mathrm{~mL})$ was added dropwise to a solution of undec10-enyl 4-(3-(4-oxo-6-tridecyl-1,4-dihydropyrimidin-2-yl)ureido) benzoate $(150 \mathrm{mg}, 0.25 \mathrm{mmol})$ in degassed chloroform $(10 \mathrm{~mL})$ and the reaction mixture was stirred at room temperature for 2 days. It was then filtered through celite before the solvent was evaporated and the resultant solid was crystallised $\left(\mathrm{CHCl}_{3}-\right.$ $\mathrm{MeOH})$ to give (E,Z)-icos-10-ene-1,20-diyl-bis(4-(3-(4-oxo-6-tridecyl-1,4-dihydropyrimidin-2-yl)ureido)benzoate) (125 mg, $84 \%)$ as an off white powder; $\delta_{\mathrm{H}}\left(300 \mathrm{MHz}, \mathrm{CDCl}_{3}\right) ; 12.59$ (2H, br, NH) 12.40 (2H, br, NH), $11.90(2 \mathrm{H}, \mathrm{br}, \mathrm{NH}), 7.91(4 \mathrm{H}$, br, $\mathrm{ArCH}), 7.75(4 \mathrm{H}, \mathrm{br}, \mathrm{ArCH}) 5.60(0.5 \mathrm{H}, \mathrm{br}, \mathrm{CH}), 5.45(0.5 \mathrm{H}$, br, $\mathrm{CH}), 5.35$ (1H, br, $\mathrm{CH}), 4.18\left(4 \mathrm{H}, \mathrm{br}, \mathrm{CH}_{2}\right), 1.92(4 \mathrm{H}, \mathrm{br}$, $\left.\mathrm{CH}_{2}\right), 1.68\left(4 \mathrm{H}, \mathrm{br}, \mathrm{CH}_{2}\right), 1.20\left(72 \mathrm{H}, \mathrm{br}, \mathrm{CH}_{2}\right), 0.85(6 \mathrm{H}, \mathrm{br}$, $\left.\mathrm{CH}_{3}\right)$; the molecule was insufficiently soluble to obtain a meaningful ${ }^{13} \mathrm{C}$ spectrum; ESI-HRMS found $\mathrm{m} / \mathrm{z} 1211.8188$ $[\mathrm{M}+\mathrm{Na}]^{+}, \mathrm{C}_{70} \mathrm{H}_{108} \mathrm{~N}_{8} \mathrm{NaO}_{8}$ requires 1211.8182 .

\section{(E,Z)-Bis(4-(3-(4-oxo-6-tridecyl-1,4-dihydropyrimidin-2- yl)ureido)phenyl)icos-10-enedioate 4}

Grubbs' (I) catalyst (10 mg, $0.01 \mathrm{mmol}$ ) in degassed dichloromethane $(1 \mathrm{~mL})$ was added dropwise to a solution of 4-(3-(4oxo-6-tridecyl-1,4-dihydropyrimidin-2-yl)ureido)phenyl undec10-enoate $(150 \mathrm{mg}, 0.25 \mathrm{mmol})$ in degassed dichloromethane $(10 \mathrm{~mL})$ and the reaction mixture was stirred at room temperature for 2 days. It was then filtered through celite before the solvent was evaporated and the resultant solid was precipitated (chloroform : methanol) to give $(E, Z)$-bis(4-(3-(4oxo-6-tridecyl-1,4-dihydropyrimidin-2-yl)ureido)phenyl)icos-10enedioate $(140 \mathrm{mg}, 93 \%)$ as an off white powder; $\delta_{\mathrm{H}}(300 \mathrm{MHz}$, $\left.\mathrm{CDCl}_{3}\right) ; 12.80(2 \mathrm{H}, \mathrm{br}, \mathrm{NH}), 12.30(2 \mathrm{H}, \mathrm{br}, \mathrm{NH}), 11.95(2 \mathrm{H}, \mathrm{br}$, $\mathrm{NH}), 7.70(4 \mathrm{H}, \mathrm{br}, \mathrm{ArCH}), 6.95(4 \mathrm{H}, \mathrm{br}, \mathrm{ArCH}), 5.60(2 \mathrm{H}, \mathrm{br}$, $\mathrm{CH}), 5.42(2 \mathrm{H}, \mathrm{br}, \mathrm{CH}), 2.60\left(4 \mathrm{H}, \mathrm{br}, \mathrm{CH}_{2}\right), 1.90\left(4 \mathrm{H}, \mathrm{br}, \mathrm{CH}_{2}\right)$, $1.70\left(4 \mathrm{H}, \mathrm{br}, \mathrm{CH}_{2}\right), 1.20\left(68 \mathrm{H}, \mathrm{br}, \mathrm{CH}_{2}\right), 0.75\left(6 \mathrm{H}, \mathrm{br}, \mathrm{CH}_{3}\right)$; the molecule was insufficiently soluble to obtain a meaningful ${ }^{13} \mathrm{C}$ 
spectrum; ESI-HRMS found $m / z \quad 1183.7869 \quad[\mathrm{M}+\mathrm{Na}]^{+}$, $\mathrm{C}_{68} \mathrm{H}_{104} \mathrm{~N}_{8} \mathrm{NaO}_{8}$ requires 1183.7869 .

\section{DOSY experiments}

DOSY NMR measurements were made on a Varian Inova 500 $\mathrm{MHz}$ spectrometer. All experiments were conducted at $20{ }^{\circ} \mathrm{C}$ on $\mathrm{CDCl}_{3}$ solutions, and used a $5 \mathrm{~mm}$ ID probe. The bipolar pulse pair simulated echo (BPPSTE) sequence ${ }^{24}$ was employed operating in ONESHOT mode. ${ }^{25}$ Additional parameters: number of different gradient strengths, 20; gradient stabilisation delay $0.002 \mathrm{~s}$; gradient length $0.002 \mathrm{~s}$; diffusion delay 0.03 $\mathrm{s}$; relaxation delay $2.5 \mathrm{~s}$ (following measurement of $\mathrm{T} 1$ ); acquisition time $2 \mathrm{~s}$; kappa (unbalancing factor, 0.2). Data were processed using a $3 \mathrm{~Hz}$ line broadening and exponential multiplication. Data were zero-filled once. Spectra were phased and baseline corrected prior to production of the pseudo 2D DOSY plots. For measurement of diffusion coefficients, a calibration curve was plotted (using the Stokes-Einstein relationship) for diffusion coefficient $\left(\times 10^{6} \mathrm{~cm}^{2} \mathrm{~s}^{-1}\right)$ versus the reciprocal cube root of the molecular mass $(1 /$ (molecular mass $)^{1 / 3}$ ) as described previously. ${ }^{14}$

\section{Acknowledgements}

This work was supported by the Leverhulme Trust [F/00122/ AN].

\section{References}

1 R. J. Wojtecki, M. A. Meador and S. J. Rowan, Nat. Mater., 2011, 10, 14-27.

2 T. Aida, E. W. Meijer and S. I. Stupp, Science, 2012, 335, 813-817.

3 S. Burattini, B. W. Greenland, D. Chappell, H. M. Colquhoun and W. Hayes, Chem. Soc. Rev., 2010, 39, 1973-1985.

4 J. D. Fox and S. J. Rowan, Macromolecules, 2009, 42, 6823-6835.

5 A. J. Wilson, Soft Matter, 2007, 3, 409-425.

6 L. Brunsveld, B. J. B. Folmer, E. W. Meijer and R. P. Sijbesma, Chem. Rev., 2001, 101, 4071-4097.
7 W. H. Binder, S. Bernstorff, C. Kluger, L. Petraru and M. J. Kunz, Adv. Mater., 2005, 17, 2824-2428.

8 S. Sivakova, D. A. Bohnsack, M. E. Mackay, P. Suwanmala and S. J. Rowan, J. Am. Chem. Soc., 2005, 127, 18202-18211.

9 W. C. Yount, D. M. Loveless and S. L. Craig, Angew. Chem., Int. Ed., 2005, 44, 2746-2748.

10 H. Kautz, D. J. M. van Beek, R. P. Sijbesma and E. W. Meijer, Macromolecules, 2006, 39, 4265-4267.

11 S. C. Zimmerman and P. S. Corbin, Struct. Bonding, 2000, 96, 63-94.

12 A. Gooch, A. M. McGhee, L. C. Renton, J. P. Plante, C. I. Lindsay and A. J. Wilson, Supramol. Chem., 2009, 21, 12-17.

13 A. Gooch, A. M. McGhee, M. L. Pellizzaro, C. I. Lindsay and A. J. Wilson, Org. Lett., 2011, 13, 240-243.

14 M. L. Pellizzaro, A. M. McGhee, L. C. Renton, M. G. Nix, J. Fisher, W. B. Turnbull and A. J. Wilson, Chem.-Eur. J., 2011, 17, 14508-14517.

15 M. L. Pellizzaro, S. A. Barrett, J. Fisher and A. J. Wilson, Org. Biomol. Chem., 2012, 10, 4899-4906.

16 A. Gooch, C. Nedolisa, K. A. Houton, C. I. Lindsay, A. Saiani and A. J. Wilson, Macromolecules, 2012, 45, 4723-4729.

17 F. H. Beijer, R. P. Sijbesma, H. Kooijman, A. L. Spek and E. W. Meijer, J. Am. Chem. Soc., 1998, 120, 6761-6769.

18 S. H. M. Söntjens, R. P. Sijbesma, M. H. P. van Genderen and E. W. Meijer, Macromolecules, 2001, 34, 3815-3818.

19 E. Greco, A. E. Aliev, V. G. H. Lafitte, K. Bala, D. Duncan, L. Pilon, P. Golding and H. C. Hailes, New J. Chem., 2010, 34, 2634-2642.

20 V. G. H. Lafitte, A. E. Aliev, E. Greco, K. Bala, P. Golding and H. C. Hailes, New J. Chem., 2011, 35, 1522-1527.

21 T. F. A. de Greef, M. M. L. Nieuwenhuizen, P. J. M. Stals, C. F. C. Fitie, A. R. A. Palmans, R. P. Sijbesma and E. W. Meijer, Chem. Commun., 2008, 4306-4308.

22 Z. Chen, A. M. Venkatesan, C.M. Dehnhardt, S. AyralKaloustian, N. Brooijmans, R. Mallon, L. Feldberg, I. Hollander, J. Lucas, K. Yu, F. Kong and T. S. Mansour, J. Med. Chem., 2010, 53, 3169-3182.

23 A. M. Salaheldin, A. M. F. Oliveira-Campos, P. Parpot, L. M. Rodrigues, M. M. Oliveira and F. P. Feixoto, Helv. Chim. Acta, 2010, 93, 242-248.

24 M. D. Pelta, H. Barjat, G. A. Morris, A. L. Davis and S. J. Hammond, Magn. Reson. Chem., 1998, 36, 706-714.

25 M. D. Pelta, G. A. Morris, M. J. Stchedroff and S. J. Hammond, Magn. Reson. Chem., 2002, 40, S147-S152. 